\title{
Efeito do pré-tratamento osmótico com sacarose e cloreto de sódio sobre a secagem convectiva de abóbora
}

\author{
Effect of osmotic pre-treatment with sucrose and sodium chloride \\ on convective drying of pumpkin \\ Isabella BORIN ${ }^{1}$, Elen Cristina FRASCARELI ${ }^{1}$, Maria Aparecida MAURO $^{1 \star}$, Mieko KIMURA ${ }^{1}$
}

\begin{abstract}
Resumo
O objetivo deste trabalho foi avaliar os efeitos de pré-tratamentos osmóticos sobre a cinética de secagem de fatias de abóbora (Cucurbita moschata) e sobre características sensoriais do produto seco, utilizando sacarose e $\mathrm{NaCl}$ como solutos. Condições de pré-tratamento foram selecionadas com base na relação perda de água/ganho de solutos e na limitação de conteúdo de sal no produto final. Amostras tratadas nas condições selecionadas (50\% de sacarose; $47 \%$ de sacarose e 3\% de $\mathrm{NaCl} ; 40 \%$ de sacarose; $37 \%$ de sacarose e $3 \% \mathrm{de} \mathrm{NaCl}$, p/p, 1 hora) e amostras não tratadas foram secas com ar aquecido a $70^{\circ} \mathrm{C}, 2 \mathrm{~m} / \mathrm{s}$. A cinética de secagem foi descrita pela Segunda Lei de Fick. Coeficientes de difusão efetivos de água foram determinados considerando-se a espessura inicial e a espessura média das fatias durante a secagem. As difusividades determinadas em amostras tratadas e não tratadas resultaram próximas quando a espessura média foi utilizada. Amostras tratadas apresentaram taxas de secagem maiores que amostras sem tratamento, mostrando que os pré-tratamentos melhoraram a eficiência do processo. Os tratamentos também melhoram a cor e a aparência geral das fatias secas, em relação às amostras sem tratamento.

Palavras-chave: sacarose; cloreto de sódio; abóbora; desidratação osmótica; cinética de secagem; coeficientes efetivos de difusão.
\end{abstract}

\begin{abstract}
The objective of this work was to evaluate the effects of osmotic pre-treatments on the air-drying kinetics of sliced pumpkin (Cucurbita moschata) and on the sensory quality of the dried pumpkin, using sucrose and $\mathrm{NaCl}$ as solutes. Pre-treatment conditions in osmotic solutions were selected based on the water loss/solute gain ratio and on the final salt content. Pre-treated samples in the selected conditions (50\% sucrose; $47 \%$ sucrose and $3 \% \mathrm{NaCl} ; 40 \%$ sucrose; $37 \%$ sucrose and $3 \% \mathrm{NaCl}$, w/w, 1 hour) and non-treated samples were dried at $70{ }^{\circ} \mathrm{C}$, $2 \mathrm{~m} / \mathrm{s}$. The drying kinetics was described according to Fick's Second Law. Effective diffusion coefficients were determined considering the initial thickness and the average thickness of the slices during air-drying. The effective water diffusivities of pre-treated and non-treated samples were similar when average thickness was used. Drying rates of the treated samples were higher than those of the non-treated samples, showing that the pre-treatments enhanced the efficiency of convective drying. The color and the general appearance of the dried pumpkin were improved by the previous treatments in comparison to the non-treated samples.

Keywords: sucrose; sodium chloride; pumpkin; osmotic dehydration; drying kinetics; effective diffusion coefficients.
\end{abstract}

\section{Introdução}

A abóbora (Curcubita moschata) é uma espécie indígena americana com significativa participação na alimentação de muitos países (RAMOS et al., 1999; WHITAKER; CARTER, 1946; WHITAKER; CUTLER, 1965) devido às suas características nutricionais e à coloração atrativa. Algumas variedades são boas fontes de carotenóides, principalmente $\alpha$-caroteno e $\beta$-caroteno (ARIMA; RODRIGUEZ-AMAYA, 1988; AZEVEDO-MELEIROS, 2003). Além da importante atividade pró-vitamínica A, os carotenóides possuem função antioxidante (ARIMA; RODRIGUEZ-AMAYA, 1988; RODRIGUEZAMAYA, 2002), que trazem benefícios à saúde, reduzindo o risco de doenças cardiovasculares e cânceres (KRINSK, 1993).

A desidratação osmótica (DO) de um alimento sólido é uma técnica que envolve a imersão do mesmo em solução aquosa hipertônica (SERENO et al., 2001). Durante este processo, ocorrem três tipos de transferência de massa com fluxo contracorrente: fluxo de água do sólido para solução, transferência de soluto da solução para o sólido e fluxo de solutos do sólido para a solução (RAOULT-WACK, 1994).

A taxa de remoção de água durante a desidratação osmótica depende de diversos fatores, tais como: concentração e temperatura da solução, tempo de contato, grau de agitação da solução, forma e tamanho do sólido, razão solução/sólido e nível de vácuo, se aplicado (RASTOGI et al., 1997). Os efeitos da concentração de soluto, da temperatura e do tempo de contato têm sido estudados em um grande número de produtos, como por exemplo: em banana (MAURO; MENEGALLI, 1995; RASTOGI et al., 1997), pêssego (ASKAR et al., 1996), maçã (HAWKES; FLINK, 1978; QUINTERO-RAMOS et al., 1993; SERENO et al., 2001) e cenoura (QI et al., 1998).

Recebido para publicação em 8/6/2006

Aceito para publicação em 17/12/2007 (001754)

Departamento de Engenharia e Tecnologia de Alimentos, Instituto de Biociências, Letras e Ciências Exatas - IBILCE, Universidade Estadual Paulista - UNESP,

Rua Cristóvão Colombo, 2265, CEP 15054-000, São José do Rio Preto - SP, Brasil, E-mail: cidam@ibilce.unesp.br

${ }^{*}$ A quem a correspondência deve ser enviada 
A escolha do soluto é uma questão fundamental por estar relacionada com as alterações nas propriedades organolépticas e no valor nutritivo do produto final, além do custo de processo (LENART, 1996; QI et al., 1998). Características do agente osmótico usado, como peso molecular e comportamento iônico, afetam significativamente a desidratação, tanto na quantidade de água removida quanto no ganho de sólidos (ERTEKIN; CAKALOZ, 1996). A sacarose é tida como um ótimo agente osmótico, especialmente quando a DO é empregada como etapa preliminar à secagem convectiva, pois previne o escurecimento enzimático e a perda de aromas (LENART, 1996; QI et al., 1998). O uso do cloreto de sódio como agente osmótico é desejável quando um gosto de sal mantém ou melhora o sabor do produto processado. É também um excelente agente osmótico, até mesmo quando combinado com a sacarose. Essa combinação foi bastante efetiva na desidratação osmótica de maçãs, porém, seu uso como substituto da sacarose não obteve boa aceitação em testes organolépticos devido ao gosto salgado incorporado à fruta (HAWKES; FLINK, 1978). A eficiência do $\mathrm{NaCl}$ foi também observada na desidratação osmótica de tomate cereja, mas o seu baixo peso molecular permitiu alta penetração no tecido. Soluções combinadas de sacarose-sal reduziram a penetração do mesmo, porém, a taxa de perda de água também foi reduzida (AZOUBEL; MURR, 2004).

Em geral, o objetivo da desidratação osmótica é maximizar a perda de água, e ao mesmo tempo, minimizar o ganho de soluto por parte do sólido (QI et al., 1998). Contudo, a DO geralmente não é capaz de abaixar a atividade de água a níveis que dispensem técnicas adicionais para conservação de alimentos. A secagem convectiva, por sua vez, diminui consideravelmente o teor de água no produto, o que minimiza o crescimento de microrganismos e reações de deterioração química, preservando-o durante a estocagem (MAYOR; SERENO, 2003), além de contribuir para a redução de custos de embalagem, transporte e armazenamento.

A principal vantagem da desidratação osmótica como prétratamento antes da secagem convectiva de alimentos é que ela minimiza os impactos negativos desta última, como perda de aroma, escurecimento enzimático e perda da cor natural dos alimentos (PONTING et al., 1966; QUINTERO-RAMOS et al., 1993). Fatias de carambola secas a $60{ }^{\circ} \mathrm{C}$ podem apresentar melhor aparência e sabor quando pré-tratadas em solução de sacarose $(50 \%, \mathrm{p} / \mathrm{p})$ (SHIGEMATSU et al., 2005). Efeito protetor sobre a estrutura do alimento, gerando produtos mais flexíveis e macios, também tem sido observado (LENART, 1996).

O objetivo do presente trabalho foi avaliar a influência de pré-tratamentos osmóticos sobre a cinética de secagem convectiva e sobre a qualidade sensorial de abóboras desidratadas, utilizando $\mathrm{NaCl}$ e sacarose como solutos.

\section{Material e métodos}

\subsection{Material}

Abóboras (Curcubita moschata), da variedade Seca Melhorada, no estágio maduro, com aproximadamente $30 \mathrm{~kg}$, foram adquiridas no mercado local - CEAGESP (São José do Rio
Preto) e armazenadas em temperatura ambiente. Os agentes osmóticos foram sacarose (açúcar refinado comercial) e $\mathrm{NaCl}$ (sal comercial).

\subsection{Metodologia experimental}

\section{Preparação das amostras}

Devido ao seu tamanho (média de $30 \mathrm{~kg}$ ), as abóboras tiveram as pontas desprezadas e foram segmentadas transversalmente em três peças para facilitar a manipulação. As peças foram quarteadas no sentido longitudinal e duas partes opostas de cada uma foram combinadas e usadas para o mesmo experimento. Após a remoção da casca e do miolo, de tecido esponjoso, os quartos foram cortados mais uma vez no sentido longitudinal para diminuir o seu tamanho e então foram fatiados em cortador elétrico de frios (marca Eco), regulado para espessura de $0,4 \mathrm{~cm}$.

\section{Seleção dos tratamentos osmóticos}

Ensaios preliminares foram realizados com o objetivo de verificar a influência das soluções de açúcar e sal, e do tempo de tratamento, sobre a eficiência da desidratação osmótica. A eficiência foi medida considerando-se a relação entre perda de água e ganho de solutos durante a DO.

Em um primeiro ensaio, fatias de abóboras foram desidratadas em soluções aquosas com 50, 40 e $30 \%$ de sacarose e em soluções combinadas de sacarose- $\mathrm{NaCl}$, com 45-5, 35-5 e 25-5\% $\mathrm{p} / \mathrm{p}$, durante 1 e 2 horas $\left(27^{\circ} \mathrm{C}\right)$. Para a condução simultânea dos ensaios com as diversas soluções osmóticas e com uma mesma abóbora, foram utilizados recipientes cilíndricos de vidro de $800 \mathrm{~mL}$, com tampa, em incubadora refrigerada (Marconi, modelo MA 830/A) com plataforma de agitação orbital (160 rpm) e temperatura controlada $\left(27^{\circ} \mathrm{C}\right)$. Aproximadamente $50 \mathrm{~g}$ de fatias de abóbora foram desidratadas em $800 \mathrm{~g}$ de solução, em duplicata. A massa, os sólidos totais e o teor de sódio foram medidos antes e depois da DO. O teor de açúcares totais e redutores foi determinado nas amostras antes da DO. O teor de açúcar, após a DO, foi calculado por diferença, através de balanços de massa.

Devido ao elevado teor de sódio apresentado pelas amostras tratadas em soluções contendo $5 \%$ de $\mathrm{NaCl}$, fez-se um segundo ensaio, no qual as concentrações de sal foram reduzidas na preparação das soluções. As novas combinações de sacarose- $\mathrm{NaCl}$ foram $47-3,37-3$ e $27-3 \%$ p/p (1 e 2 horas, a $27^{\circ} \mathrm{C}$ ).

\section{Processamento}

Com os tratamentos osmóticos selecionados como os mais eficientes, realizaram-se os ensaios de secagem convectiva, onde a desidratação osmótica foi conduzida numa escala maior que a utilizada na pré-seleção.

\section{Desidratação osmótica}

Quatro cestos construídos em nylon, com repartição no meio e dispondo de tampa de aço inoxidável em cada uma das partes, foram utilizados para comportar as amostras (aproximadamen- 
te $200 \mathrm{~g}$ em cada cesto). Estes foram dispostos dentro de uma cuba quadrada construída em aço inoxidável, de dimensões de $30 \times 30 \times 35 \mathrm{~cm}$, com camisa externa. Utilizaram-se aproximadamente $20 \mathrm{~kg}$ de solução aquosa preparada com açúcar e água destilada, ou com combinações de açúcar e sal. A agitação da solução foi conduzida por um agitador mecânico com 1,6 kw de potência (Marconi, modelo MA-261), com hélice naval $(10 \mathrm{~cm}$ de diâmetro) e com rotação de $1000 \mathrm{rpm}$. A temperatura da solução foi mantida em $27{ }^{\circ} \mathrm{C}$ por meio de água circulando na camisa externa, bombeada a partir de um banho ultratermostatizado (Marconi, modelo MA-184) que dispõe de refrigeração.

O tempo de processo pré-selecionado foi de 1 hora. Após esse tempo, as amostras foram retiradas do banho osmótico e limpas com pano umedecido e papel absorvente. Amostras representativas foram pesadas e homogeneizadas em um mixer, para a realização das análises de sólidos totais, sódio, açúcares redutores e totais.

\section{Secagem convectiva}

Amostras sem pré-tratamento e tratadas osmoticamente nas condições selecionadas foram desidratadas a $70{ }^{\circ} \mathrm{C}$ em secador que dispõe de um ventilador centrífugo (Ibram, modelo CV3600) com motor de $2 \mathrm{CV}$, e câmara de secagem com área transversal de $961 \mathrm{~cm}^{2}(31 \times 31 \mathrm{~cm})$, onde a velocidade do ar foi controlada em $2 \mathrm{~m} / \mathrm{s}$ por um inversor de freqüência (WEG, $\mu$ line, modelo ML-7.0/200-240) ligado ao motor do ventilador. Acoplada ao secador há uma balança semi-analítica (Gehaka, modelo BG 4000), com precisão de 0,01 g e capacidade para 4.000 g. Esta dispõe de uma interface RS232 para a transmissão de dados a um microcomputador, onde foram registrados os valores de peso ao longo do tempo. Foi utilizado um programa fornecido pelo fabricante da balança, compatível com planilhas eletrônicas do Excel da Microsoft. Para controle da temperatura, foi utilizado um controlador microprocessado com indicação digital (Novus, modelo N480D), com sensor tipo PT 100. O prato da balança foi substituído por uma estrutura construída para apoiar três bandejas de tela metálica, dispostas paralelamente ao fluxo de ar, nas quais foram distribuídas em cada uma aproximadamente $100 \mathrm{~g}$ de fatias de abóbora. As amostras ficavam acomodadas entre duas telas de metal, para impedir deformação exagerada durante a secagem. $O$ processo foi conduzido com recirculação total do ar, sendo que este passava por uma barreira de $2 \mathrm{~cm}$ de espessura, constituída por esferas de sílica gel dispostas entre duas telas metálicas, homogeneizando o fluxo. Temperatura de bulbo úmido e seco foram medidas antes e depois da câmara de secagem. A velocidade do ar foi mantida relativamente alta $(2 \mathrm{~m} / \mathrm{s})$, com o intuito de minimizar a influência da resistência externa. Com isso, considerou-se como condição de superfície a concentração de água de equilíbrio obtida ao fim da secagem, quando o peso não variou mais com o tempo. Açúcares totais e redutores e teor de sódio foram determinados antes das secagens, enquanto que os sólidos totais foram determinados antes e depois de cada secagem.

\subsection{Métodos analíticos}

Para a determinação de açúcares totais e redutores, a metodologia adotada foi a titulação de óxido-redução (WILLIAM,
1970). A concentração de sódio foi determinada pelo método de espectrofotometria de chama (WILLIANS, 1984) em fotômetro (Digimed, modelo DM-61). A determinação dos sólidos totais foi realizada por secagem em estufa a vácuo a $60^{\circ} \mathrm{C}$ e $10 \mathrm{kPa}$, até peso constante.

\subsection{Avaliação sensorial}

Para avaliar o efeito dos pré-tratamentos na aceitação de cor, aparência geral e sabor do produto, fatias de abóbora tratadas e sem tratamento e secas a $70{ }^{\circ} \mathrm{C}$ por um período de 6 horas, foram avaliadas sensorialmente por uma equipe de 26 provadores não treinados, utilizando escala hedônica estruturada de nove pontos. Os resultados foram tratados estatisticamente por análise de variância (ANOVA) e teste de Tuckey utilizando o programa Excel-Microsoft.

\subsection{Análise dos resultados}

\section{Desidratação osmótica}

A eficiência da DO foi calculada, para cada tratamento, com base na perda de água e ganho de solutos, determinada por meio do levantamento de dados experimentais de massas, teores de sólidos totais, teores de sódio e, em determinados ensaios, açúcares totais e redutores. Com base neste levantamento, foram realizados os balanços de massa.

A variação de massa $(\Delta \mathrm{M})$ em relação à massa inicial é representada abaixo por:

$\Delta \mathrm{M}=\frac{\mathrm{M}-\mathrm{M}^{0}}{\mathrm{M}^{0}}$

em que M é a massa após um tempo t de desidratação osmótica, e $\mathrm{M}^{0}$ a massa no tempo inicial $(\mathrm{t}=0)$.

A perda de água $\left(\Delta \mathrm{P}_{\mathrm{a}}\right)$ e o ganho de sacarose $\left(\Delta \mathrm{G}_{\mathrm{sac}}\right)$ em relação à massa inicial podem ser calculados para cada tempo de processo, segundo:

$$
\begin{aligned}
& \Delta \mathrm{P}_{\mathrm{a}}=\frac{\left(\mathrm{M} \mathrm{W}_{\mathrm{a}}\right)-\left(\mathrm{M}^{0} \mathrm{~W}_{\mathrm{a}}^{0}\right)}{\mathrm{M}^{0}} \\
& \Delta \mathrm{G}_{\mathrm{sac}}=\frac{\left(\mathrm{M} \mathrm{W}_{\mathrm{sac}}\right)-\left(\mathrm{M}^{0} \mathrm{~W}_{\mathrm{sac}}^{0}\right)}{\mathrm{M}^{0}}
\end{aligned}
$$

com $\mathrm{W}_{\mathrm{a}}$ e $\mathrm{W}_{\mathrm{sac}}$ representando, respectivamente, o teor de água e o teor de sacarose, após um tempo t de desidratação osmótica, e $\mathrm{W}_{\mathrm{a}}^{0}$ e $\mathrm{W}_{\mathrm{sac}}^{0}$, os mesmos teores na abóbora fresca, em $\mathrm{t}=0$.

O ganho de sal $\left(\Delta \mathrm{G}_{\mathrm{sal}}\right)$, para os experimentos que utilizaram soluções combinadas de sacarose- $\mathrm{NaCl}$, é calculado de forma similar, através da equação:

$$
\Delta \mathrm{G}_{\text {sal }}=\frac{\left(\mathrm{M} \mathrm{W}_{\mathrm{sal}}\right)-\left(\mathrm{M}^{0} \mathrm{~W}_{\mathrm{sal}}^{0}\right)}{\mathrm{M}^{0}}
$$

em que $\mathrm{W}_{\text {sal }}$ representa o teor de sal após um tempo t de processo e $\mathrm{W}_{\text {sal }}^{0}$ o teor inicial de sal na abóbora fresca, em $\mathrm{t}=0$. 
A eficiência (E) é medida pela relação entre perda de água e ganho de sólidos:

$$
\mathrm{E}=\frac{\Delta \mathrm{P}_{\mathrm{a}}}{\Delta \mathrm{G}_{\text {soluto }}}
$$

em que $\Delta \mathrm{G}_{\text {soluto }}$ se refere ao ganho de sacarose ou de sacarose + sal.

\section{Secagem convectiva}

Na secagem de frutas e hortaliças, a maior parte do processo transcorre no período de taxa decrescente. Para se descrever o processo de secagem de abóboras em fatias, pré-tratadas ou não, utilizou-se a Segunda Lei de Fick, apresentada na forma geral, a seguir:

$$
\frac{\partial \mathrm{X}}{\partial \mathrm{t}}=\mathrm{D}_{\mathrm{ef}} \nabla^{2} \mathrm{X}
$$

em que X é a fração de massa de água, em base seca (bs), $\mathrm{D}_{\mathrm{ef}}$ é o coeficiente efetivo de difusão e $t$, o tempo de secagem.

Como o fenômeno de migração é complexo, trabalha-se com uma difusividade efetiva, que engloba todos os efeitos que podem intervir nesse fenômeno. As soluções analíticas para a Segunda Lei de Fick aplicam-se a sólidos de formas geométricas simples e constantes ao longo do processo. Considerou-se que o sólido é uma placa plana infinita, com ambas as superfícies expostas ao ar de secagem, sua difusividade efetiva é constante e o efeito do gradiente de temperatura no interior da amostra é desprezível. Tem-se a seguinte solução analítica, na forma integrada, isto é, em termos de concentração média, na placa, num tempo t (CRANK, 1975):

$$
X=\frac{\bar{X}(t)-X^{\text {eq }}}{X^{0}-X^{\text {eq }}}=\frac{8}{\pi^{2}} \sum_{n=1}^{\infty} \frac{1}{(2 n-1)^{2}} \exp \left[-(2 n-1)^{2} \frac{\pi^{2} D_{\text {ef }} t^{-}}{L^{2}}\right.
$$

em que $\mathbf{X}$ é a umidade média adimensional, sendo $\bar{X}(t)$ a fração média de massa de água (bs) obtida na placa num tempo t. $\mathrm{X}^{0}$ e $\mathrm{X}^{\mathrm{eq}}$ são frações de massa de água (bs), em que 0 representa o instante inicial $(t=0)$ e eq, o equilíbrio. L é a espessura da amostra.

O conteúdo de umidade na amostra inicial foi considerado homogêneo, desprezando-se o perfil de concentração existente nas amostras pré-tratadas:

$\mathrm{X}=\mathrm{X}^{0}, \mathrm{t}=0,-\mathrm{L} / 2 \leq \mathrm{z} \leq \mathrm{L} / 2$

A resistência externa, durante a secagem, foi considerada desprezível devido à alta velocidade do ar. A concentração na interface é representada pelo conteúdo de água na amostra, em equilíbrio com o ar de secagem, isto é:

$\mathrm{X}=\mathrm{X}^{\mathrm{eq}}, \mathrm{t}>0, \mathrm{z}= \pm \mathrm{L} / 2$

No plano central da fatia, o gradiente de concentração é nulo: $\left.\frac{\partial \mathrm{X}}{\partial \mathrm{z}}\right|_{\mathrm{z}=0}=0, \quad \mathrm{t} \geq 0$

Foi utilizada uma "espessura média", calculada entre a espessura inicial e a espessura ao fim da secagem, com o intuito de considerar, de forma aproximada, o encolhimento que ocorre durante a secagem, uma vez que este é muito significativo. As espessuras das fatias, após a DO e após a secagem, foram calculadas considerando-se que os volumes são aditivos, isto é, que são adicionados como componentes puros, no caso, água, sacarose e sal, principais espécies que difundiram através do sistema. Esse procedimento se baseia na baixa porosidade do tecido de abóbora, verificada em estudo prévio sobre a densidade da abóbora fresca tratada osmoticamente em soluções de sacarose $(60 \%, \mathrm{p} / \mathrm{p})$ e desidratada a 50 e $70{ }^{\circ} \mathrm{C}$, em que a redução de volume medida durante a $\mathrm{DO}$ e a secagem resultou semelhante à soma da variação calculada dos volumes de água e sacarose (GARCIA et al., 2007).

A razão entre o volume do sólido $(\mathrm{V})$ após um tempo de processo (desidratação osmótica ou secagem) e o volume inicial $\left(\mathrm{V}^{0}\right)$, foi calculada segundo:

$$
\frac{\mathrm{V}}{\mathrm{V}^{0}}=\frac{\mathrm{V}-\mathrm{V}^{0}}{\mathrm{~V}^{0}}+1=\sum_{\mathrm{k}}\left(\frac{\mathrm{M} \mathrm{W}-\mathrm{M}^{0} \mathrm{~W}_{\mathrm{k}}^{0}}{\mathrm{~V}^{0} \rho_{\mathrm{k}}}\right)+1
$$

em que $M$ representa a massa após um tempo de processo, $\mathrm{M}^{0}$ é a massa inicial, $W_{\mathrm{k}}$ e $\mathrm{W}_{\mathrm{k}}^{0}$ representam, respectivamente, a fração de massa (bu) final e inicial da substância $\mathrm{K}$ ( $\mathrm{K}=\mathrm{a}$ (água), sac (sacarose) ou sal $(\mathrm{NaCl})$, dependendo do processo), e $\rho_{\mathrm{k}}$ representa a densidade dessas substâncias puras. Por fim, a variação na espessura foi calculada considerando-se que o encolhimento ocorre igualmente em todas as dimensões.

Taxas de secagem foram avaliadas através dos fluxos de massa de água evaporada $(\mathrm{N})$, expressos como massa/(área $\mathrm{X}$ tempo). Para tanto foram determinadas pequenas variações no conteúdo de umidade $(\Delta \mathrm{X})$ e correspondente variação no tempo $(\Delta \mathrm{t})(\mathrm{TREYBAL}, 1980)$ :

$$
\mathrm{N}=-\mathrm{m}_{\mathrm{s}} \frac{\Delta \mathrm{X}}{\mathrm{S} \Delta \mathrm{t}}
$$

em que $m_{s}$ representa a massa de sólidos secos e $\mathrm{S}$ a superfície úmida através da qual a evaporação ocorre, calculada com a consideração de encolhimento.

\section{Resultados e discussão}

\subsection{Pré-tratamentos}

Teor final de umidade, variação total de massa (Equação 1), perda de água (Equação 2), ganho de sacarose e ganho de sal (Equação 4) e eficiência de processo (Equação 5) são apresentados após 1 hora (Tabela 1) e 2 horas (Tabela 2) de desidratação osmótica de fatias de abóbora em diferentes soluções de sacarose e sacarose- $\mathrm{NaCl}$. O ganho de sacarose foi calculado por diferença, subtraindo-se $\Delta \mathrm{P}_{\mathrm{a}}$ e, quando pertinente, $\Delta \mathrm{G}_{\text {sal }}$ de $\Delta \mathrm{M}$. 
De maneira geral, a eficiência foi maior quando as fatias foram tratadas com soluções compostas de sacarose- $\mathrm{NaCl}$ que continham 3\% de sal, por 1 hora. A rápida perda de água, em comparação com o ganho de solutos, é freqüentemente observada nos primeiros 30 minutos de DO (KOWALSKA; LENART, 2001).

A influência do sal sobre a perda de água foi significativa devido à capacidade de abaixamento da atividade de água por parte do $\mathrm{NaCl}$, quando adicionado à solução de sacarose, o que é facilmente demonstrado pela aplicação da equação de Ross (1975). No entanto, quando se compara uma solução de sacarose que contém $3 \%$ de sal com a correspondente contendo $5 \%$, a perda de água em relação à massa inicial diminui com o aumento da concentração de sal, o que poderia ser justificado pelo elevado ganho de sólidos (Tabelas 1 e 2). É possível que isso decorra de alterações na estrutura celular, viabilizando mais espaços intracelulares para a difusão da sacarose. Além disso, as membranas celulares são permeáveis aos íons $\mathrm{Na}^{+} \mathrm{e} \mathrm{Cl}^{-}$(BIDWELL, 1979), permitindo grande impregnação desse soluto.

$\mathrm{Na}$ Tabela 3 estão reportados os teores finais de sacarose e $\mathrm{NaCl}$ no produto, em base seca, sendo que o teor de sódio é 2,54 vezes menor que o de $\mathrm{NaCl}$.

Constata-se que o comportamento da impregnação de sal e açúcar pode variar bastante com o tempo e com a combinação de solutos. De maneira geral, quanto maior o teor de sacarose

Tabela 1. Média e desvio padrão de teor de água $\left(\mathrm{W}_{\mathrm{a}}\right)$, variação de massa $(\Delta \mathrm{M})$, perda de água $\left(\Delta \mathrm{P}_{\mathrm{a}}\right)$, ganho de sacarose $\left(\Delta \mathrm{G}_{\mathrm{sac}}\right)$ e ganho de sal $\left(\Delta \mathrm{G}_{\text {sal }}\right)$, em relação à massa inicial $\left(\mathrm{M}^{0}\right)$ das amostras, e eficiência $(\mathrm{E})$, após 1 hora de desidratação osmótica em frascos com diferentes soluções de sacarose e sacarose- $\mathrm{NaCl}$.

\begin{tabular}{|c|c|c|c|c|c|c|c|}
\hline \multicolumn{2}{|c|}{ Concentração da solução osmótica (\% p/p) } & \multirow[t]{2}{*}{$\mathrm{W}_{\mathrm{a}}(\%)$} & \multirow[t]{2}{*}{$\Delta \mathrm{M}(\%)$} & \multirow[t]{2}{*}{$\Delta \mathrm{Pa}(\%)$} & \multirow{2}{*}{$\Delta \mathrm{G}_{\mathrm{sac}}(\%)$} & \multirow{2}{*}{$\Delta \mathrm{G}_{\mathrm{sal}}(\%)$} & \multirow[t]{2}{*}{$\mathrm{E}(\%)$} \\
\hline Sacarose & $\mathrm{NaCl}$ & & & & & & \\
\hline 50 & 0 & $72,99 \pm 0,07$ & $-37,30 \pm 0,79$ & $-46,95 \pm 0,57$ & $9,65 \pm 0,21$ & - & $-4,87 \pm 0,17$ \\
\hline 47 & 3 & $65,90 \pm 0,07$ & $-53,06 \pm 2,79$ & $-61,03 \pm 1,84$ & $7,42 \pm 0,92$ & $0,55 \pm 0,03$ & $-7,73 \pm 1,15$ \\
\hline 45 & 5 & $65,27 \pm 0,04$ & $-39,06 \pm 1,90$ & $-52,94 \pm 1,24$ & $11,40 \pm 0,58$ & $2,48 \pm 0,08$ & $-3,82 \pm 0,27$ \\
\hline 40 & 0 & $77,93 \pm 0,12$ & $-29,54 \pm 0,88$ & $-37,80 \pm 0,68$ & $8,26 \pm 0,19$ & - & $-4,58 \pm 0,19$ \\
\hline 37 & 3 & $68,93 \pm 0,10$ & $-48,10 \pm 1,01$ & $-56,19 \pm 0,69$ & $7,34 \pm 0,30$ & $0,74 \pm 0,01$ & $-6,95 \pm 0,35$ \\
\hline 35 & 5 & $67,92 \pm 0,09$ & $-40,78 \pm 1,49$ & $-52,49 \pm 1,01$ & $9,54 \pm 0,42$ & $2,17 \pm 0,05$ & $-4,49 \pm 0,27$ \\
\hline 30 & 0 & $83,08 \pm 0,04$ & $-25,73 \pm 2,25$ & $-31,01 \pm 1,87$ & $5,29 \pm 0,38$ & - & $-5,90 \pm 0,78$ \\
\hline 27 & 3 & $73,78 \pm 0,16$ & $-44,05 \pm 1,68$ & $-50,68 \pm 1,24$ & $5,81 \pm 0,42$ & $0,83 \pm 0,03$ & $-7,66 \pm 0,70$ \\
\hline 25 & 5 & $73,83 \pm 0,06$ & $-38,03 \pm 0,56$ & $-46,97 \pm 0,41$ & $6,84 \pm 0,13$ & $2,09 \pm 0,02$ & $-5,26 \pm 0,13$ \\
\hline
\end{tabular}

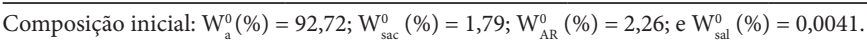

Tabela 2. Média e desvio padrão de teor de água $\left(\mathrm{W}_{\mathrm{a}}\right)$, variação de massa $(\Delta \mathrm{M})$, perda de água $\left(\Delta \mathrm{P}_{\mathrm{a}}\right)$, ganho de sacarose $\left(\Delta \mathrm{G}_{\mathrm{sac}}\right)$ e ganho de sal $\left(\Delta \mathrm{G}_{\mathrm{sal}}\right)$, em relação à massa inicial $\left(\mathrm{M}^{0}\right)$ das amostras, e eficiência $(\mathrm{E})$, após 2 horas de desidratação osmótica em frascos com diferentes soluções de sacarose e sacarose- $\mathrm{NaCl}$.

\begin{tabular}{|c|c|c|c|c|c|c|c|}
\hline \multicolumn{2}{|c|}{ Concentração da solução osmótica (\% p/p) } & \multirow[t]{2}{*}{$\mathrm{W}_{\mathrm{a}}(\%)$} & \multirow[t]{2}{*}{$\Delta \mathrm{M}(\%)$} & \multirow[t]{2}{*}{$\Delta \mathrm{P}_{\mathrm{a}}(\%)$} & \multirow[t]{2}{*}{$\Delta \mathrm{G}_{\mathrm{sac}}(\%)$} & \multirow{2}{*}{$\Delta \mathrm{G}_{\mathrm{sal}}(\%)$} & \multirow[t]{2}{*}{$\mathrm{E}(\%)$} \\
\hline Sacarose & $\mathrm{NaCl}$ & & & & & & \\
\hline 50 & 0 & $65,23 \pm 0,13$ & $-44,90 \pm 0,48$ & $-56,78 \pm 0,31$ & $11,87 \pm 0,17$ & - & $-4,78 \pm 0,09$ \\
\hline 47 & 3 & $53,85 \pm 0,15$ & $-60,14 \pm 0,14$ & $-70,50 \pm 0,08$ & $9,64 \pm 0,07$ & $0,72 \pm 0,04$ & $-6,80 \pm 0,05$ \\
\hline 45 & 5 & $52,11 \pm 0,11$ & $-51,77 \pm 0,74$ & $-67,58 \pm 0,39$ & $13,79 \pm 0,32$ & $2,02 \pm 0,03$ & $-4,28 \pm 0,12$ \\
\hline 40 & 0 & $71,53 \pm 0,02$ & $-38,34 \pm 0,91$ & $-48,61 \pm 0,65$ & $10,27 \pm 0,26$ & - & $-4,74 \pm 0,18$ \\
\hline 37 & 3 & $60,26 \pm 0,06$ & $-53,78 \pm 1,78$ & $-64,12 \pm 1,08$ & $9,49 \pm 0,40$ & $0,85 \pm 0,03$ & $-6,22 \pm 0,53$ \\
\hline 35 & 5 & $60,26 \pm 0,10$ & $-46,88 \pm 1,49$ & $-60,71 \pm 0,90$ & $11,72 \pm 0,53$ & $2,10 \pm 0,06$ & $-4,40 \pm 0,15$ \\
\hline 30 & 0 & $79,29 \pm 0,03$ & $-30,78 \pm 1,70$ & $-37,83 \pm 1,35$ & $7,05 \pm 0,35$ & - & $-5,38 \pm 0,46$ \\
\hline 27 & 3 & $67,77 \pm 0,16$ & $-47,40 \pm 0,40$ & $-56,32 \pm 0,27$ & $8,04 \pm 0,11$ & $0,88 \pm 0,02$ & $-6,32 \pm 0,12$ \\
\hline 25 & 5 & $68,41 \pm 0,09$ & $-39,02 \pm 0,07$ & $-51,00 \pm 0,05$ & $9,53 \pm 0,02$ & $2,45 \pm 0,00$ & $-4,26 \pm 0,01$ \\
\hline
\end{tabular}

Composição inicial: $\mathrm{W}_{\mathrm{a}}^{0}(\%)=91,97 ; \mathrm{W}_{\mathrm{sac}}^{0}(\%)=2,28 ; \mathrm{W}_{\mathrm{AR}}^{0}(\%)=2,07 ; \mathrm{e} \mathrm{W}_{\mathrm{sal}}^{0}(\%)=0,0063$.

Tabela 3. Média e desvio padrão de teor de sacarose calculado (base seca) e teor de $\mathrm{NaCl}$ medido (base seca) nas amostras desidratadas osmoticamente durante 1 e 2 horas em frascos com diferentes soluções de sacarose e sacarose- $\mathrm{NaCl}$.

\begin{tabular}{|c|c|c|c|c|c|}
\hline \multicolumn{2}{|c|}{ Concentração da solução osmótica (\% p/p) } & \multicolumn{2}{|c|}{ Sacarose g/100 g de matéria seca } & \multicolumn{2}{|c|}{$\mathrm{NaCl}$ g/100 g de matéria seca } \\
\hline Sacarose & $\mathrm{NaCl}$ & 1 hora DO & 2 horas DO & 1 hora DO & 2 horas DO \\
\hline 47 & 3 & $60,59 \pm 2,14$ & $64,82 \pm 0,11$ & $3,46 \pm 0,01$ & $3,97 \pm 0,25$ \\
\hline 45 & 5 & $62,31 \pm 0,81$ & $67,46 \pm 0,37$ & $11,73 \pm 0,90$ & $8,77 \pm 0,11$ \\
\hline 37 & 3 & $59,71 \pm 0,69$ & $64,07 \pm 1,21$ & $4,66 \pm 0,43$ & $4,64 \pm 0,21$ \\
\hline 35 & 5 & $59,65 \pm 0,73$ & $64,01 \pm 0,73$ & $11,43 \pm 0,13$ & $9,97 \pm 0,33$ \\
\hline 27 & 3 & $55,14 \pm 1,18$ & $60,88 \pm 0,26$ & $5,69 \pm 0,35$ & $5,24 \pm 0,42$ \\
\hline 25 & 5 & $53,20 \pm 0,30$ & $58,76 \pm 0,03$ & $12,93 \pm 0,28$ & $12,73 \pm 0,18$ \\
\hline
\end{tabular}


na solução e maior o tempo de DO, maior será o conteúdo de sacarose e menor o de sal impregnado (Tabela 3). Isso está relacionado ao ganho de solutos após 1 hora (Tabela 1) e 2 horas (Tabela 2) de processo. O ganho de sal em geral ocorreu preponderantemente na primeira hora de $\mathrm{DO}$, enquanto que o de sacarose prosseguiu na segunda hora de processo. Portanto, a massa de sacarose contribuiu para diminuir o teor de sal na massa seca total, após 2 horas de DO, o que foi significativo nas composições de sacarose- $\mathrm{NaCl}$ com 45-5 e 35-5\%, mas não na composição com 25-5\%, e tampouco nos tratamentos com 3\% de sal na composição da solução.

A partir desses resultados preliminares de eficiência de DO e teor de sódio obtido no produto final, foram selecionadas as seguintes condições de tratamento osmótico: soluções aquosas com 50 e $40 \%$ de sacarose e soluções combinadas de sacarose$\mathrm{NaCl}$ com $47-3$ e $37-3 \%$, durante o tempo de 1 hora.

\subsection{Secagem osmo-convectiva}

Abóboras em fatias, sem tratamento ou pré-tratadas em soluções osmóticas com 50 e $40 \%$ de sacarose, e 47-3 e 37-3\% de sacarose- $\mathrm{NaCl}$, foram submetidas à secagem a $70{ }^{\circ} \mathrm{C}$, por 1 hora

A composição média das amostras frescas utilizadas nos experimentos foi de 93,53 $\pm 1,30 \%$ de umidade, $1,00 \pm 0,47 \%$ de sacarose, e 2,36 \pm 0,23\% de açúcares redutores.

A umidade relativa (UR) do ar de secagem, durante os diferentes ensaios, foi em média de $8,3 \%$. A máxima diferença entre o dia mais seco (UR $=7 \%)$ e o mais úmido (UR $=10 \%)$ foi de $3 \%$. Devido à recirculação do ar no secador, constatouse pequena variação da umidade relativa durante a primeira meia hora de secagem, caindo em média de 11,7 para $8,7 \%$, e estabilizando-se a seguir.

Alguns ensaios de secagem foram repetidos, sendo que os identificados pela letra (A) foram conduzidos durante o tempo necessário para as amostras entrarem em equilíbrio com as condições do ar aquecido, o que variou entre 8 e 10 horas de secagem. Nos ensaios identificados pela letra (B), a partir dos quais foram preparadas as amostras para a avaliação sensorial, as secagens foram conduzidas por 6 horas. A identificação com a letra (C) significou repetição do padrão estabelecido no ensaio (A). Além disso, em relação aos pré-tratamentos dos ensaios (A), as análises de açúcares e sódio foram conduzidas nas amostras frescas e desidratadas osmoticamente, enquanto que nos ensaios (B), somente as amostras frescas foram analisadas e, portanto, o ganho de solutos foi calculado pela diferença entre a variação de massa e a água perdida $\left(\Delta \mathrm{M}-\Delta \mathrm{P}_{\mathrm{a}}\right)$.

Na Tabela 4 estão apresentados os teores médios de água (bu) analisados na abóbora sem tratamento $\left(\mathrm{W}_{\mathrm{a}}^{0}\right)$, após a DO $\left(\mathrm{W}_{\mathrm{a}}^{\mathrm{D}}\right)$ e após a secagem $\left(\mathrm{W}_{\mathrm{a}}^{\mathrm{S}}\right)$. Notam-se variações entre o teor inicial de água das diversas abóboras frescas e uma significativa diferença entre o teor de água das amostras após a desidratação osmótica em solução de sacarose- $\mathrm{NaCl}$ a 47-3\%. Esse comportamento tem sido observado em abóbora e parece estar mais relacionado à estrutura do tecido, como dureza e constituição fibrosa, do que à umidade inicial.

A Tabela 5 mostra a variação total de massa (Equação 1), a perda de água (Equação 2), o ganho de sacarose (Equação 3), o ganho de sal (Equação 4) e a eficiência do processo (Equação 5) determinados durante os ensaios de DO que precederam as correspondentes secagens.

Observa-se que o máximo de perda de água ocorreu quando o tratamento osmótico foi conduzido em soluções com a presença de sal, o que não significou máxima eficiência em todos os casos. No entanto, é possível observar mais uma vez que as duplicatas dos ensaios demonstram diferenças consideráveis. Ao mesmo tempo, os desvios padrão, dentro de um mesmo ensaio, são baixos, mostrando que, quando é utilizada uma mesma abóbora, há pouca diferença entre as diversas amostras.

As espessuras das fatias, após a DO e após a secagem, foram calculadas a partir da variação de volume das amostras, considerando-se que os volumes de água, sal e sacarose podem ser adicionados como componentes puros (Equação 11), aproximação baseada na baixa porosidade observada na variedade de abóbora utilizada neste trabalho (GARCIA et al., 2007).

A densidade da sacarose $\left(1.588 \mathrm{~kg} / \mathrm{m}^{3}\right)$ (PERRY; CHILTON, 1973), do $\mathrm{NaCl}\left(2.163 \mathrm{~kg} / \mathrm{m}^{3}\right)$ (PERRY; CHILTON, 1973) e da

Tabela 4. Média e desvio padrão do teor de água medido nas fatias de abóbora em base úmida, nas amostras sem tratamento (0), após a desidratação osmótica (DO) em cuba e ao fim da secagem $(\mathrm{S})$ a $70^{\circ} \mathrm{C}$; teor de água lido na curva experimental de secagem $^{(*)}$.

\begin{tabular}{|c|c|c|c|c|c|c|}
\hline \multicolumn{3}{|c|}{ Concentração na solução osmótica (\% p/p) } & \multirow[t]{2}{*}{$\mathrm{W}_{\mathrm{a}}^{0}(\%)$} & \multirow[t]{2}{*}{$\mathrm{W}_{\mathrm{a}}^{\mathrm{DO}}(\%)$} & \multirow{2}{*}{$\begin{array}{l}\mathrm{W}_{\mathrm{a}}^{\mathrm{s}}(\%) \\
6 \text { horas }\end{array}$} & \multirow{2}{*}{$\begin{array}{c}\mathrm{W}_{\mathrm{a}}^{\mathrm{s}}(\%) \\
\text { equilíbrio }\end{array}$} \\
\hline Sacarose & $\mathrm{NaCl}$ & & & & & \\
\hline 50 & 0 & (A) & $92,63 \pm 0,13$ & $76,22 \pm 0,29$ & $4,18^{(*)}$ & $3,45 \pm 0,09$ \\
\hline \multirow[t]{2}{*}{47} & 3 & (A) & $93,80 \pm 0,06$ & $62,51 \pm 0,23$ & $3,95^{(*)}$ & $3,31 \pm 0,03$ \\
\hline & & (B) & $92,90 \pm 0,08$ & $73,78 \pm 0,58$ & $5,17 \pm 0,22$ & - \\
\hline \multirow[t]{2}{*}{40} & 0 & (A) & $93,13 \pm 0,12$ & $79,14 \pm 0,09$ & $4,19^{(*)}$ & $3,26 \pm 0,15$ \\
\hline & & (B) & $91,36 \pm 0,71$ & $78,74 \pm 0,44$ & $4,31 \pm 0,07$ & - \\
\hline \multirow[t]{2}{*}{37} & 3 & (A) & $94,63 \pm 0,10$ & $72,72 \pm 0,18$ & $4,59^{(*)}$ & $3,89 \pm 0,70$ \\
\hline & & (B) & $91,57 \pm 0,03$ & $73,01 \pm 1,01$ & $5,13 \pm 0,06$ & - \\
\hline \multirow{3}{*}{\multicolumn{2}{|c|}{ Sem tratamento }} & (A) & $91,16 \pm 0,04$ & - & $3,16^{(*)}$ & $2,53 \pm 0,09$ \\
\hline & & (B) & $92,78 \pm 0,03$ & - & $2,11 \pm 0,11$ & - \\
\hline & & (C) & $94,78 \pm 0,03$ & - & $6,35^{(*)}$ & $2,54^{(*)}$ \\
\hline
\end{tabular}

(A): secagem até peso constante; (B): secagem por 6 horas; e (C): secagem até peso constante. 
abóbora in natura $\left(1.011 \mathrm{~kg} / \mathrm{m}^{3}\right)$ (GARCIA et al., 2007), assim como a variação das massas de água, de sacarose e de sal, foram utilizadas no cálculo de encolhimento (Tabela 6) e subseqüente cálculo de espessura, considerando que todas as dimensões do sólido encolheram igualmente. Como os conteúdos finais de sacarose e de sal não foram medidos separadamente nos ensaios (B), um ganho médio de sal foi estimado com base nos resultados dos ensaios (A) para calcular o encolhimento, pois ainda que a proporção de sacarose/sal não seja exatamente a mesma entre os dois experimentos, a aproximação é razoável, dada a baixa quantidade de sal impregnada no tecido nas condições de tempo e concentração utilizadas.

As variações volumétricas calculadas durante a DO das fatias imersas em soluções compostas de sacarose- $\mathrm{NaCl}$ (Tabela 6) tendem a ser superiores àquelas observadas nas amostras tratadas somente com sacarose. As amostras que tiveram maior redução do volume durante a DO apresentaram menor variação durante a secagem. Isso resulta numa redução volumétrica total (DO + secagem) muito semelhante entre todas as amostras tratadas, o que mostra a contribuição dos sólidos impregnados no volume final das mesmas.

O conteúdo de água em base seca e em função do tempo é apresentado para as secagens de abóbora sem tratamento na
Figura 1. Constata-se a significativa diferença de conteúdo inicial de água entre as abóboras utilizadas, o que separa as curvas, durante as primeiras 2 horas de secagem.

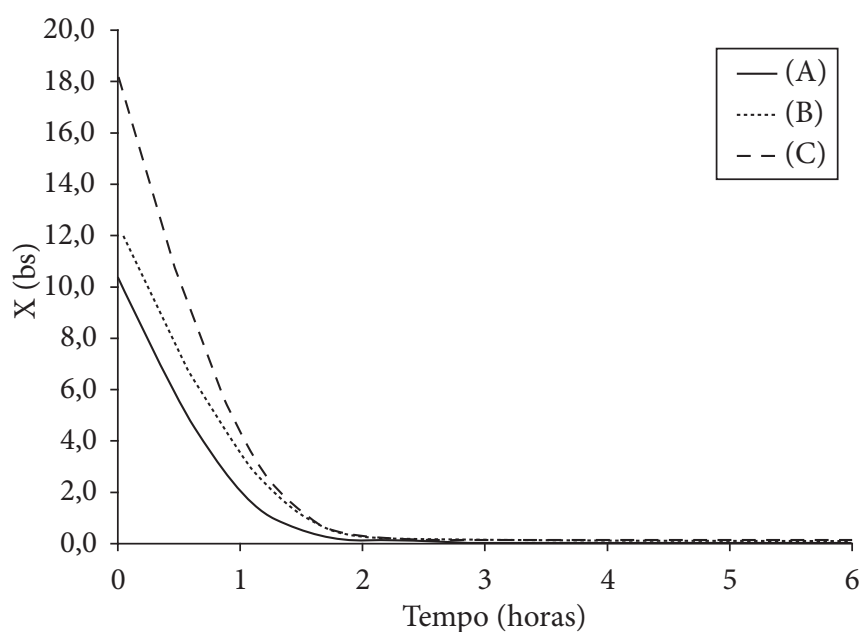

Figura 1. Comparação entre curvas de secagem a $70{ }^{\circ} \mathrm{C}$ das abóboras sem pré-tratamento. (A) secagem até peso constante; (B) - secagem por 6 horas; e $(C)$ - secagem até peso constante.

Tabela 5. Média e desvio padrão de variação de massa $(\Delta \mathrm{M})$, perda de água $\left(\Delta \mathrm{P}_{\mathrm{a}}\right)$, ganho de sacarose $\left(\Delta \mathrm{G}_{\mathrm{sac}}\right)$ e ganho de sal $\left(\Delta \mathrm{G}_{\text {sal }}\right)$, em relação à massa inicial $\left(\mathrm{M}^{0}\right)$, e eficiência $(\mathrm{E})$, após 1 hora de desidratação osmótica em cuba, em diferentes soluções de açúcar e açúcar-sal, previamente à secagem.

\begin{tabular}{|c|c|c|c|c|c|c|c|}
\hline \multicolumn{2}{|c|}{ Concentração na solução osmótica (\% p/p) } & & \multirow[t]{2}{*}{$\Delta \mathrm{M}$} & \multirow[t]{2}{*}{$\Delta \mathrm{P}_{\mathrm{a}}$} & \multirow[t]{2}{*}{$\Delta \mathrm{G}_{\mathrm{sac}}$} & \multirow[t]{2}{*}{$\Delta \mathrm{G}_{\mathrm{sal}}$} & \multirow[t]{2}{*}{$\mathrm{E}$} \\
\hline Sacarose & $\mathrm{NaCl}$ & & & & & & \\
\hline 50 & 0 & (A) & $-34,44 \pm 1,09$ & $-42,66 \pm 0,83$ & $6,22 \pm 0,14$ & - & $-6,86 \pm 0,29$ \\
\hline \multirow[t]{2}{*}{47} & 3 & $(\mathrm{~A})$ & $-60,13 \pm 1,02$ & $-68,87 \pm 0,64$ & $6,82 \pm 0,20$ & $0,85 \pm 0,02$ & $-8,98 \pm 0,35$ \\
\hline & & (B) & $40,07 \pm 0,80$ & $-48,68 \pm 0,59$ & \multicolumn{2}{|c|}{$8,61^{(*)}$} & $-5,66 \pm 0,21$ \\
\hline \multirow[t]{2}{*}{40} & 0 & $(\mathrm{~A})$ & $-33,54 \pm 0,85$ & $-40,53 \pm 0,67$ & $6,64 \pm 0,10$ & - & $-6,11 \pm 0,20$ \\
\hline & & (B) & $-29,02 \pm 1,69$ & $-35,47 \pm 1,33$ & $6,45^{(* *)}$ & - & $-5,52 \pm 0,51$ \\
\hline \multirow[t]{2}{*}{37} & 3 & $(\mathrm{~A})$ & $-45,92 \pm 1,07$ & $-55,30 \pm 0,78$ & $7,25 \pm 0,16$ & $1,20 \pm 0,02$ & $-6,55 \pm 0,23$ \\
\hline & & (B) & $-34,84 \pm 1,35$ & $-43,99 \pm 0,99$ & \multicolumn{2}{|c|}{$9,15^{(*)}$} & $-4,81 \pm 0,31$ \\
\hline
\end{tabular}

(A): açúcares e sódio analisados nas amostras frescas e desidratadas osmoticamente; (B) açúcares e sódio analisados somente nas amostras frescas; (*) ganho de solutos $\left(\Delta \mathrm{G}_{\text {sac }}+\Delta \mathrm{G}_{\text {sal }}\right)$ calculado por diferença: $\left(\Delta \mathrm{M}-\Delta \mathrm{P}_{\mathrm{a}}\right) ; \mathrm{e}^{(*)}$ ganho de sacarose $\left(\Delta \mathrm{G}_{\mathrm{sac}}\right)$ calculado por diferença: $\left(\Delta \mathrm{M}-\Delta \mathrm{P}_{\mathrm{a}}\right)$.

Tabela 6. Variação volumétrica calculada para abóboras durante o processo de desidratação osmótica (DO) em cuba, durante o processo de secagem (S) e encolhimento total (DO + secagem).

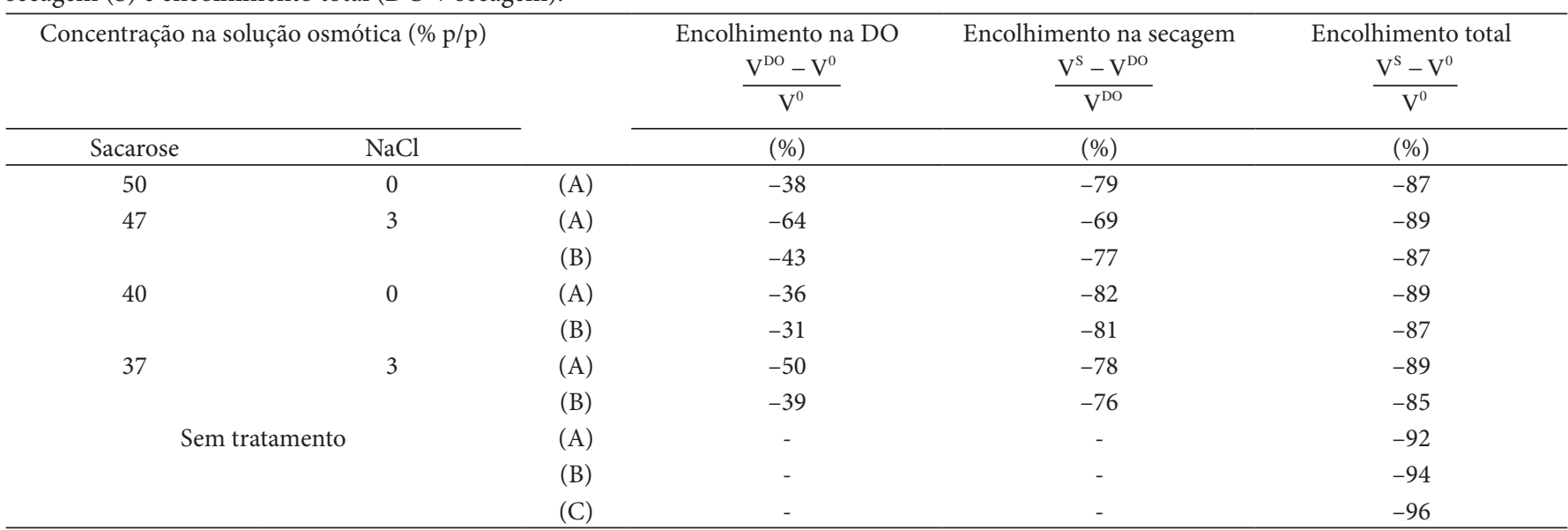

(A): secagem até peso constante; (B): secagem por 6 horas; e (C): secagem até peso constante. 
O fluxo de massa de água evaporada (Equação 12) durante a secagem de abóboras sem pré-tratamento, em função da umidade (Figura 2), mostra um aumento das taxas com as umidades inicias, representando a adaptação da amostra que entra no secador com temperatura mais baixa que do ar de secagem. A seguir, numa estreita faixa de umidade a taxa se mostra constante para em seguida decrescer com a diminuição do conteúdo de umidade das amostras. Constata-se comportamento diferente entre o ensaio (A), cuja abóbora apresentava menor teor de umidade inicial, e os ensaios (B) e (C), com abóboras mais úmidas.

Efeitos da diferença entre o conteúdo inicial de água sobre as curvas de secagem são menos proeminentes quando as amostras são pré-tratadas (Figura 3), o que é atribuído ao nível mais baixo de umidade do tecido tratado. Entretanto, isso pôde ser detectado entre os ensaios (A) e (B) correspondentes ao tratamento em solução de sacarose- $\mathrm{NaCl}$ a $47-3 \%$.

O fluxo de massa de água evaporada (Equação 13), durante a secagem das amostras pré-tratadas osmoticamente (Figura 4), é maior para as amostras tratadas em soluções contendo $\mathrm{NaCl}$. Excepcionalmente o ensaio (A) em solução de sacarose- $\mathrm{NaCl}$ a 47-3\% apresentou umidade inicial bem mais baixa que as demais e um fluxo muito elevado.

Os fluxos de massa de água evaporada determinados numa mesma umidade apresentaram valores maiores em amostras tratadas (Figura 4) do que em amostras sem tratamento (Figura 2).

O peso das amostras foi registrado a cada segundo durante todo o período de secagem. Portanto, para determinar os coeficientes de difusão da água (Equação 7), selecionaram-se em torno de 10 pontos experimentais. A equação foi ajustada aos dados experimentais, utilizando-se quatro termos da série, com base na minimização do quadrado dos resíduos relativos. Os coeficientes efetivos foram determinados com a espessura L, calculada como a média entre a espessura final e a inicial, e também foram determinados com a espessura inicial, para efeito de comparação com resultados obtidos em outros traba-

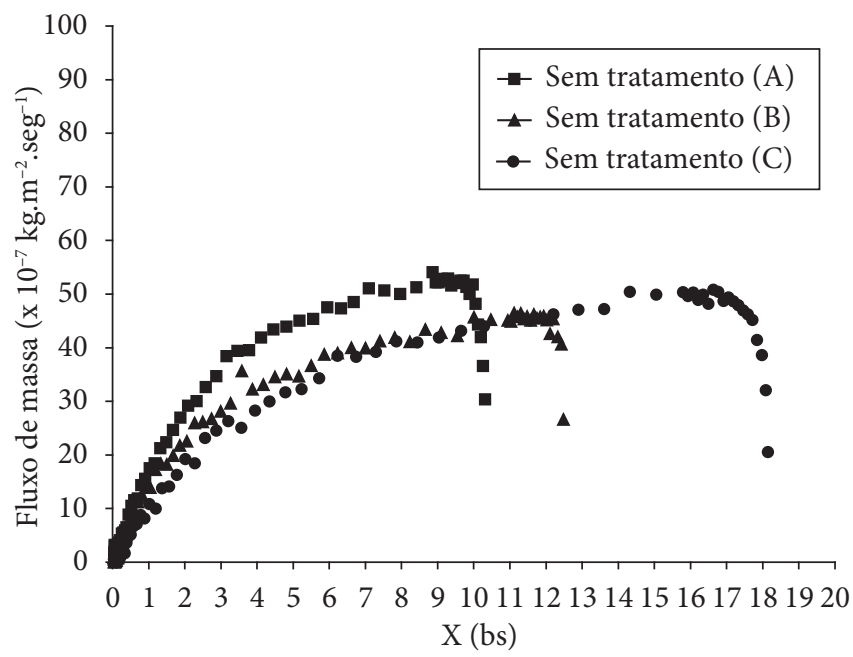

Figura 2. Comparação entre o fluxo de massa de água em abóboras sem pré-tratamento durante a secagem com ar aquecido a $70^{\circ} \mathrm{C}$. (A) secagem até peso constante; (B) - secagem por 6 horas; e (C) - secagem até peso constante. lhos, uma vez que isso é usualmente encontrado na literatura (VACAREZZA; CHIRIFE, 1975). Ainda que a utilização da solução analítica da Equação de Fick, integrada, não compute o encolhimento, a consideração da espessura média acarretará num valor de difusividade efetiva mais próximo ao valor real.

Os coeficientes determinados com a "espessura média” e com a "espessura inicial" estão na Tabela 7. Também são reportados os valores da Raiz Quadrada da Média dos Resíduos (RQMR), definida por:

$\operatorname{RQMR}(\%)=100\left\{1 /(\mathrm{n}-\mathrm{p}-1) \sum_{1}^{\mathrm{n}}\left[\left(\mathrm{X}^{\mathrm{exp}}-\mathrm{X}^{\text {calc }}\right) / \mathrm{X}^{\exp }\right]^{2}\right\}^{1 / 2}$

em que $\left(\mathrm{X}^{\exp }-\mathrm{X}^{\text {calc }}\right)$ é o resíduo, isto é, a diferença entre o valor experimental (exp) e o calculado (calc); n é o número de obser-

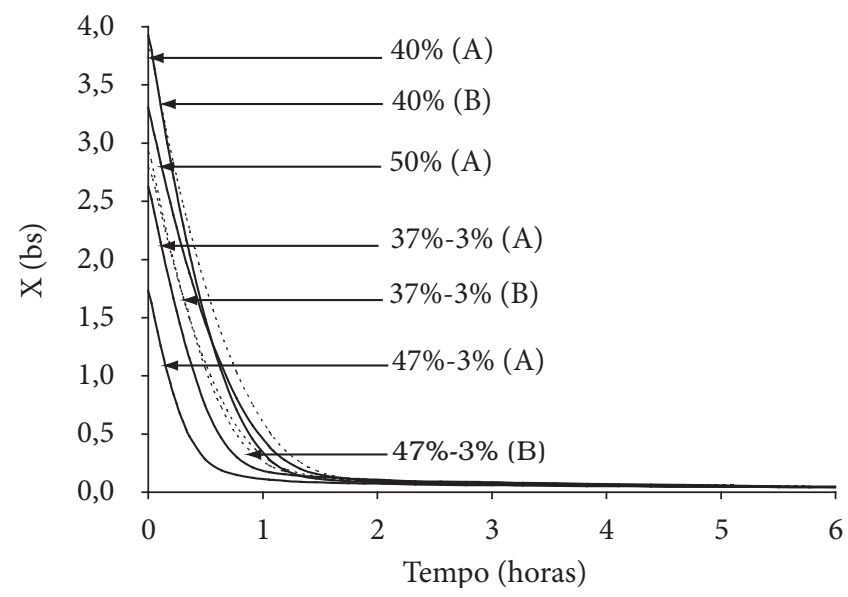

Figura 3. Comparação entre curvas de secagem a $70{ }^{\circ} \mathrm{C}$ das abóboras pré-tratadas osmoticamente. (A) - secagem até peso constante e (B) secagem por 6 horas.

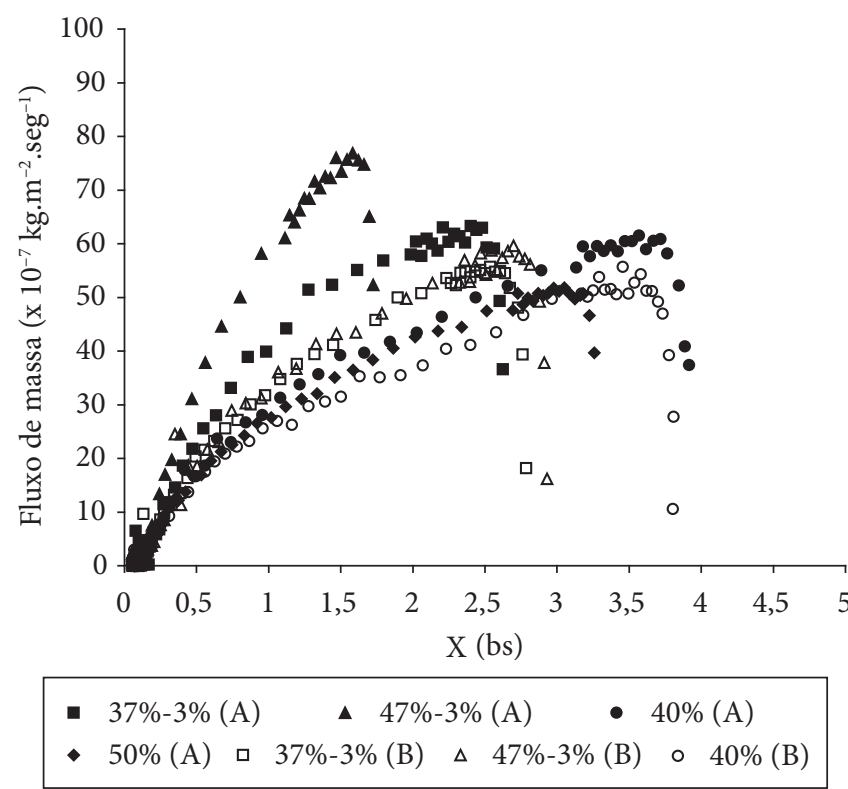

Figura 4. Comparação entre o fluxo de massa de água em abóboras pré-tratadas durante a secagem com ar aquecido a $70^{\circ} \mathrm{C}$. (A) - secagem até peso constante e (B) - secagem por 6 horas. 
vações ou resíduos; p é o número de variáveis independentes na equação ajustada e (n-p-1) define o grau de liberdade. Assim como no ajuste do modelo foram utilizados resíduos relativos, $\mathrm{RMQR}$ foi calculado relativamente ao valor experimental. Entretanto, os pequenos valores de $\mathrm{X}$ nos últimos estágios de secagem aumentam consideravelmente o valor de RQMR.

Os coeficientes efetivos determinados com a espessura inicial resultaram maiores que aqueles determinados com a espessura média (Tabela 7), como esperado. A espessura praticamente não altera a eficiência do ajuste, sendo RMQR semelhante em ambos os casos. Quando as espessuras médias são utilizadas nos cálculos, os solutos parecem não afetar significativamente a difusividade efetiva da água, uma vez que os valores resultam bastante parecidos. Entretanto, com as espessuras iniciais as diferenças tornam-se maiores e a difusividade da água nas amostras frescas passa a ser superior à difusividade nas pré-tratadas. Isso demonstra a importância de se considerar o encolhimento na secagem de materiais altamente deformáveis, bem como as limitações do uso de soluções analíticas da equação de difusão, na forma integrada, para análise desses processos.

A presença de solutos impregnados no tecido vegetal geralmente diminui a eficiência da secagem (KARATHANOS et al., 1995; RAHMAN; LAMB, 1991; SIMAL et al., 1997). Esse comportamento é esperado quando se considera o efeito das interações da água com os sólidos solúveis, que são maiores do que as interações com substâncias celulósicas e protéicas, que também constituem os tecidos vegetais (BIDWELL, 1979). Entretanto, no presente trabalho, amostras pré-tratadas apresentaram difusividades de água semelhantes às das amostras sem tratamento, quando calculadas com a espessura média. Além disso, taxas de secagem das amostras pré-tratadas foram maiores, quando comparadas às amostras sem tratamento, na mesma umidade. Uma possível explicação é que nas condições de secagem utilizadas, fatias de abóbora não tratada, cujo conteúdo de umidade é muito elevado, poderiam apresentar encolhimento rápido da superfície com formação de áreas endurecidas que aumentariam a resistência à difusão da água (PARK et al., 2003). Portanto, conclui-se que o pré-tratamento em soluções de sacarose e sacarose- $\mathrm{NaCl}$, associado às condições de $70{ }^{\circ} \mathrm{C}$ e $2 \mathrm{~m} / \mathrm{s}$, aumentou a eficiência da secagem convectiva de fatias de abóbora.

\subsection{Avaliação sensorial}

As médias e desvios padrão dos valores atribuídos pelos provadores para aparência geral, cor e sabor das fatias de abóbora secas a $70^{\circ} \mathrm{C}$, sem pré-tratamento osmótico e com prétratamento em soluções com $50 \%$ de sacarose, $47 \%$ de sacarose - 3\% de $\mathrm{NaCl}, 40 \%$ de sacarose e $37 \%$ de sacarose - 3\% de $\mathrm{NaCl}$, são apresentados na Tabela 8.

As amostras tratadas obtiveram aceitação significativamente maior que as não tratadas, tanto para o atributo cor quanto para aparência geral, mas não afetaram significativamente a aceitação do sabor.

Com relação à cor, os provadores reagiram indiferentemente à amostra sem tratamento, ou seja, nem gostaram nem desgostaram da amostra, enquanto as amostras tratadas obtiveram médias acima de 6,0 (gostei ligeiramente). Resultados similares foram encontrados para o atributo aparência. Os provadores observaram uma aparência mais rugosa na amostra não tratada e uma coloração mais intensa e brilhante nas amostras tratadas.

Embora a diferença entre a aceitação das amostras tratadas não tenha sido significativa, a distribuição de valores hedônicos atribuídos às amostras (Figura 5) mostra uma tendência para maior aceitação da cor e aparência geral das amostras submetidas ao pré-tratamento em solução com $37 \%$ de sacarose e $3 \%$ de sal.

Tabela 7. Coeficientes efetivos de difusão de água calculados na secagem a $70{ }^{\circ} \mathrm{C}$ de amostras tratadas e não tratadas, segundo Equação 7 , utilizando a "espessura média" e a "espessura inicial".

\begin{tabular}{|c|c|c|c|c|c|}
\hline \multicolumn{2}{|c|}{ Concentração na solução osmótica (\% p/p) } & & \multirow{2}{*}{$\begin{array}{c}\text { Espessura média } \\
\mathrm{D}_{\mathrm{ef}} \times 10^{10}\left(\mathrm{~m}^{2} / \mathrm{s}\right)\end{array}$} & \multirow{2}{*}{$\begin{array}{c}\text { Espessura inicial } \\
\mathrm{D}_{\mathrm{ef}} \times 10^{10}\left(\mathrm{~m}^{2} / \mathrm{s}\right)\end{array}$} & \multirow[t]{2}{*}{ RQMR (\% } \\
\hline Sacarose & $\mathrm{NaCl}$ & & & & \\
\hline 50 & 0 & (A) & 3,50 & 5,50 & 39 \\
\hline \multirow[t]{2}{*}{47} & 3 & (A) & 4,65 & 6,63 & 52 \\
\hline & & (B) & 3,59 & 5,73 & 40 \\
\hline \multirow[t]{2}{*}{40} & 0 & (A) & 4,03 & 6,53 & 46 \\
\hline & & (B) & 3,54 & 5,66 & 49 \\
\hline \multirow[t]{2}{*}{37} & 3 & (A) & 4,05 & 6,25 & 47 \\
\hline & & (B) & 3,82 & 5,80 & 38 \\
\hline \multirow{3}{*}{\multicolumn{2}{|c|}{ Sem tratamento }} & (A) & 3,60 & 7,04 & 96 \\
\hline & & (B) & 3,18 & 6,49 & 103 \\
\hline & & $(\mathrm{C})$ & 3,19 & 7,00 & 105 \\
\hline
\end{tabular}

Tabela 8. Média e desvio padrão dos valores ${ }^{(*)}$ atribuídos às amostras de fatias de abóbora tratadas e não tratadas, secas a $70{ }^{\circ} \mathrm{C}$.

\begin{tabular}{lcccccc}
\hline \multicolumn{1}{c}{ Atributo } & $\mathrm{DMS}^{(* *)}$ & Sem tratamento & $50 \%$ sacarose & $47 \% \mathrm{sac}-3 \% \mathrm{NaCl}$ & $40 \%$ sacarose & $37 \% \mathrm{sac}-3 \% \mathrm{NaCl}$ \\
\hline Cor & 1,3 & $4,7 \pm 2,2^{\mathrm{a}}$ & $6,1 \pm 1,7^{\mathrm{b}}$ & $6,1 \pm 1,7^{\mathrm{b}}$ & $6,4 \pm 1,5^{\mathrm{b}}$ & $7,3 \pm 1,2^{\mathrm{b}}$ \\
Aparência geral & 1,3 & $4,2 \pm 2,5^{\mathrm{a}}$ & $5,8 \pm 1,6^{\mathrm{b}}$ & $6,3 \pm 1,5^{\mathrm{bc}}$ & $6,8 \pm 1,3^{\mathrm{bc}}$ & $7,2 \pm 1,3^{\mathrm{c}}$ \\
Sabor & 1,6 & $5,1 \pm 2,1^{\mathrm{a}}$ & $6,0 \pm 2,0^{\mathrm{a}}$ & $5,5 \pm 2,5^{\mathrm{a}}$ & $6,4 \pm 1,3^{\mathrm{a}}$ & $5,5 \pm 2,0^{\mathrm{a}}$ \\
\hline
\end{tabular}

${ }^{(*)}$ Escala hedônica não estruturada ( 1 = desgostei muitíssimo, 9 = gostei muitíssimo); ${ }^{(*)}$ DMS diferença mínima significativa do teste de Tukey ao nível de $1 \%$; e médias na mesma linha com letras diferentes apresentam diferença significativa ao nível de $1 \%$. 

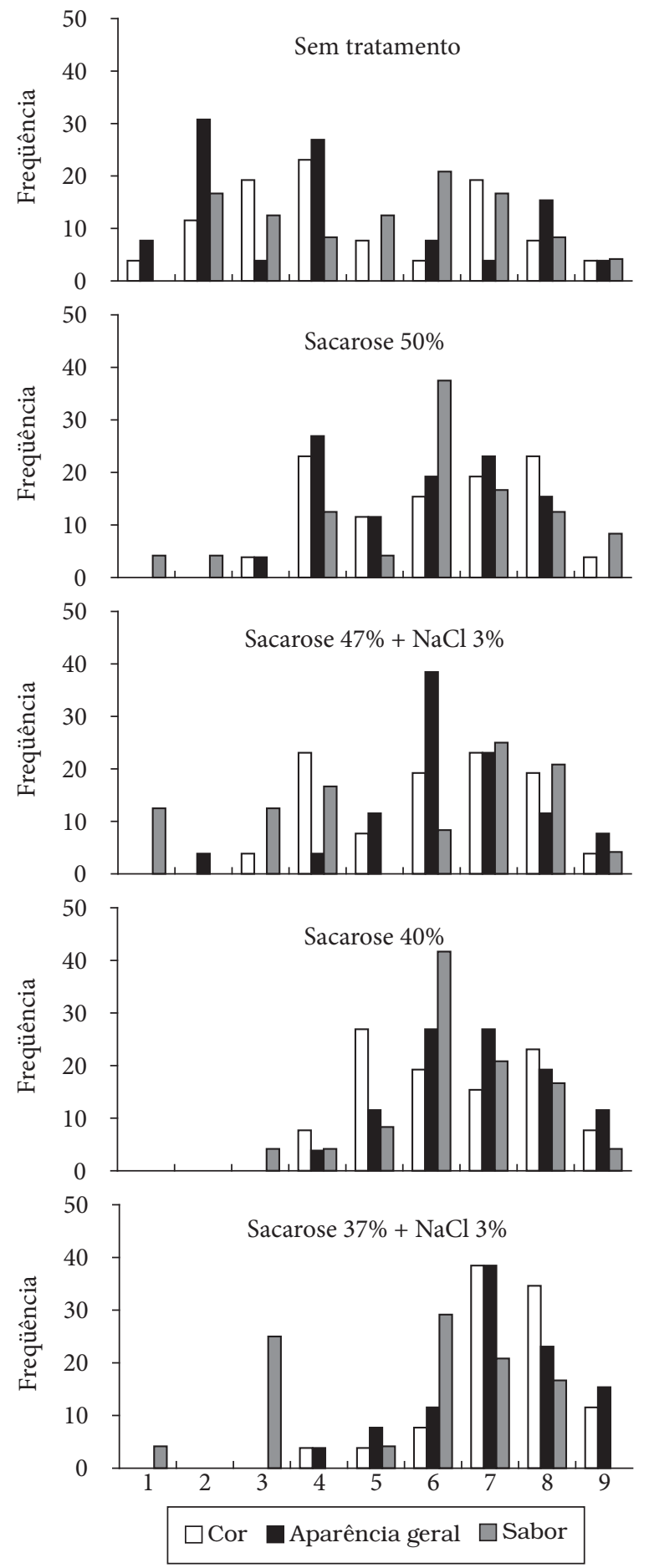

Figura 5. Distribuição da freqüência dos valores hedônicos atribuídos à cor, à aparência geral e ao sabor das amostras sem tratamento e tratadas em solução com $50 \%$ de sacarose, $47 \%$ de sacarose (3\% de sal), $40 \%$ de sacarose, e $37 \%$ de sacarose ( $3 \%$ de sal).

A baixa aceitação do sabor das amostras parece ser devido ao fato das mesmas apresentarem um sabor estranho (vegetal $\mathrm{cru}$ ) ao consumidor. O tratamento com sacarose, além de mascarar o sabor de abóbora crua conferiu um sabor adocicado, que normalmente causa uma sensação agradável aos provadores. Por outro lado, o tratamento com sacarose e $\mathrm{NaCl}$ conferiu um gosto indefinido ao produto, ou seja, nem doce nem salgado, o que pareceu desagradar mais aos provadores.

\subsection{Nomenclatura}

$\begin{array}{llc}\mathrm{E} & \text { Eficiência } & \text { adimensional } \\ \mathrm{D}_{\text {ef }} & \text { Coeficiente efetivo de difusão } & \mathrm{m}^{2} / \mathrm{s} \\ \mathrm{L} & \text { Espessura da amostra } & \mathrm{m} \\ \mathrm{M} & \begin{array}{l}\text { Massa após um tempo t de desidratação } \\ \text { osmótica }\end{array} & \mathrm{kg} \\ \mathrm{m} & \text { Massa de sólidos secos } & \\ \mathrm{N} & \text { Fluxo de massa de água evaporada } & \mathrm{kg} / \mathrm{m}^{2} \mathrm{~s} \\ \mathrm{n} & \text { Número de observações ou resíduos } & - \\ \mathrm{p} & \text { Número de variáveis independentes } & - \\ \mathrm{S} & \text { Superfície úmida através da qual a } & \mathrm{m}^{2}\end{array}$
evaporação ocorre

\section{Tempos}

UR Umidade relativa do ar de secagem

V Volume do sólido

$\mathrm{W}_{\mathrm{a}} \quad$ Teor de água (bu)

$\mathrm{W}_{\mathrm{ac}}$ Teor de sacarose (bu)

X Fração de massa de água (bs)

$\mathbf{X} \quad$ Umidade média (bs)

$\overline{\mathrm{X}}(\mathrm{t}) \quad$ Fração de massa de água (bs) média, num tempo $\mathrm{t}$

\section{z Coordenada espacial}

$\Delta \mathrm{G}_{\mathrm{sac}} \quad$ Ganho de sacarose em relação à massa inicial

$\Delta \mathrm{G}_{\text {soluto }}$ Ganho de soluto (sacarose ou sacarose + sal)

$\Delta \mathrm{P}_{\mathrm{a}} \quad$ Perda de água em relação à massa inicial

adimensional $\mathrm{m}^{3}$

adimensional adimensional adimensional adimensional adimensional

$\mathrm{m}$

adimensional

adimensional

adimensional

$\Delta \mathrm{X} \quad$ Variação da fração de massa de água (bs)

$\rho_{\mathrm{k}} \quad$ Densidade da substância k (bu)

adimensional

$\mathrm{kg} / \mathrm{m}^{3}$

\section{Sobrescritos}

\section{$0 \quad$ Inicial}

calc Calculado

eq Equilíbrio

exp Experimental

DO Desidratação osmótica

S Secagem

\begin{tabular}{ll} 
& \multicolumn{2}{c}{ Subscritos } \\
$\mathrm{sac}$ & Água \\
sal & $\mathrm{NaCl}$ \\
soluto & Soluto: sacarose ou sacarose $+\mathrm{NaCl}$ \\
$\mathrm{AR}$ & Açúcar redutor
\end{tabular}

\section{Conclusões}

A DO conduzida em soluções de sacarose e sacarose- $\mathrm{NaCl}$ durante 1 e 2 horas em geral apresentou maior eficiência na primeira hora de processo, período em que ocorre grande saída de água. A maior eficiência foi constatada em soluções de sacarose contendo 3\% de $\mathrm{NaCl}$ e a menor em soluções com $5 \%$, cujas amostras apresentaram elevado teor de $\mathrm{NaCl}$. As soluções contendo apenas sacarose apresentaram eficiência ligeiramente maior que aquelas com $5 \%$ de $\mathrm{NaCl}$. 
Na secagem convectiva, os coeficientes de difusão efetivos de água determinados com a espessura média das fatias resultaram semelhantes para amostras com e sem pré-tratamento. Diferenças obtidas entre os coeficientes de difusão calculados com a espessura inicial e com a espessura média das fatias demonstraram limitações da utilização de soluções analíticas da equação de difusão, na forma integrada, para a análise de processos de secagem de materiais altamente deformáveis.

Taxas de secagem demonstraram que a eficiência do processo aumentou quando os pré-tratamentos foram aplicados.

Os pré-tratamentos com sacarose ou sacarose- $\mathrm{NaCl}$ melhoraram significativamente a cor e a aparência geral de abóbora em fatias secas.

\section{Agradecimentos}

Os autores agradecem à FAPESP (Fundação de Amparo à Pesquisa do Estado de São Paulo), pelo apoio financeiro (Proc. 03/10151-4) e pela bolsa de estudo (Proc. 04/15550-7). Ao $\mathrm{CNPq}$, pela bolsa de estudo e ao Prof. Dr. Maurício Boscolo, pelo auxílio na realização das análises por espectrofotometria de chama.

\section{Referências bibliográficas}

ARIMA, H. K.; RODRIGUEZ-AMAYA, D. B. Carotenoid composition and vitamin A value of commercial Brazilian squashes and pumpkins. Journal of Micronutrient Analysis, Essex, England, v. 4, n. 3, p. 177-191, 1988.

ASKAR, A. et al. Osmotic and solar dehydration of peach fruits. Fruit Processing, Schonborn, Alemanha, v. 6, n. 7, p. 258-262, 1996.

AZEVEDO-MELEIROS, C. H. Análise de Carotenóides em Alimentos Brasileiros por Cromatografia Líquida de Alta Eficiência Espectrometria de Massas. Campinas, 2003. Tese (Doutor em Ciência de Alimentos), Faculdade de Engenharia de Alimentos, Universidade Estadual de Campinas (UNICAMP).

AZOUBEL, P. M.; MURR, F. E. X. Mass transfer kinetics of osmotic dehydration of cherry tomato, Journal of Food Engineering, Essex, England, v. 61, n. 3, p. 291-295, 2004.

BIDWELL, R. G. S. Plant Physiology. 2 ed. New York: Macmillan Publishing Co., 1979.

CRANK, J. The Mathematics of Diffusion. 2. ed. London: Clarendon Press-Oxford, 1975.

ERTEKIN, F. K.; CAKALOZ, T. Osmotic dehydration of peas: influence of process variables on mass transfer. Journal of Food Processing and Preservation, Westport, Conn., USA, v. 20, n. 2, p. 87-104, 1996.

GARCIA, C. C.; MAURO, M. A.; KIMURA, M. Kinetics of osmotic dehydration and air-drying of pumpkins (Cucurbita moschata). Journal of Food Engineering, Essex, England, v. 82, n. 3, p. 284-291, 2007.

HAWKES, J.; FLINK, J. M. Osmotic concentration of fruit slices prior to freeze dehydration. Journal of Food Processing and Preservation, Westport, Connecticut, USA, v. 2, n. 4, p. 265-284, 1978.

KARATHANOS, V. T.; KOSTRAPOULOS, A. E.; SARAVACOS, G. D. Air-drying of osmotically dehydrated fruits. Drying Technology, New York, US, v. 13, n. 5-7, p. 1503-1521, 1995.
KOWALSKA, H.; LENART, A. Mass exchange during osmotic pretreatment of vegetables. Journal of Food Engineering, Essex, England, v. 49, n. 2-3, p. 137-140, 2001.

KRINSKY, N. I. Actions of carotenoids in biological systems. Annual Review of Nutrition, Palo Alto, California, US, v. 13, p. 561-587, 1993.

LENART, A. Osmo-convective drying of fruits and vegetables: technology and application. Drying Technology, New York, US, v. 14, n. 2, p. 391-413, 1996.

MAURO, M. A.; MENEGALLI, F. C. Evaluation of diffusion coefficients in osmotic concentration of bananas (Musa Cavendish Lambert). International Journal of Food Science and Technology, Oxford, England, v. 30, n. 2, p. 199-213, 1995.

MAYOR, L.; SERENO, A. M. Modelling shrinkage during convective drying of food materials: a review. Journal of Food Engineering, Essex, England, v. 61, n. 3, p. 373-386, 2003.

PARK, K. J.; BIN, A.; BROD, F. P. R. Drying of Pear d'Anjou with and without Osmotic Dehydration. Journal of Food Engineering, Essex, England, v. 56, n. 1, p. 97-103, 2003.

PERRY R. H.; CHILTON, C. H. Chemical Engineers' Handbook. Fifth edition. New York: McGraw-Hill, 1973.

PONTING, J. D. et al. Osmotic dehydration of fruits. Food Technology, Chicago, Illinois, US, v. 20, n. 10, p. 125-128, 1966.

QI, H.; LE MAGUER, M.; SHARMA, S. K. Design and selection of processing conditions of a pilot scale contactor for continuous osmotic dehydration of carrots. Journal of Food Process Engineering, Westport, Connecticut, US, v. 21, n. 1, p. 75-88, 1998.

QUINTERO-RAMOS, A. et al. Effect of conditions of osmotic treatment on the quality of dried apple dices, In: BARBOSA CÁNOVAS, G. V.; OKOS, M. R. (Ed.) Food dehydration, Aiche Symposium Series, New York, NY, US, v. 89, n. 297, p. 108-103, 1993.

RAHMAN, S.; LAMB, J. Air drying behavior of fresh and osmotically dehydrated pineapple. Journal of Food Process Engineering, Westport, Connecticut, US, v. 14, n. 3, p. 163-171, 1991.

RAMOS, S. R. R. et al. Recursos genéticos de Cucurbita moschata: caracterização morfológica de populações locais coletadas no Nordeste brasileiro. In: QUEIROZ, M. A. de; GOEDERT, C. O.; RAMOS, S. R. R. (Org.). Recursos Genéticos e Melhoramento de Plantas para o Nordeste Brasileiro. v. 1, 1999. Disponível em: < http://www.herbario.com.br/dataherb13/2312recgeneabobora.htm >. Acesso em: jul. 2005.

RAOULT-WACK, A. L. Recent advances in the osmotic dehydration of foods. Trends in Food Science and Technology, Cambridge, England, v. 5, n. 8, p. 255-260, 1994.

RASTOGI, N. K.; RAGHAVARAO, K. S. M. S.; NIRANJAN, K. Mass transfer during osmotic dehydration of banana: fickian diffusion in cylindrical configuration. Journal of Food Engineering, Essex, England, v. 31, n. 4, p. 423-432, 1997.

ROSS, K. D. Estimation of water activity in intermediate moisture foods. Food Technology, Chicago, Illinois, US, v. 29, n. 3, p. 26-34, 1975.

RODRIGUEZ-AMAYA, D. B. Effects of processing and storage on food carotenoids. Sight and Life Newsletter, Special Issue, Basel, Switzerland, n. 3, p. 25-35, 2002.

SERENO, A. M.; MOREIRA, R.; MARTINEZ, E. Mass transfer coefficients during osmotic dehydration of apple in single and combined aqueous solutions of sugar and salt. Journal of Food Engineering, Essex, England, v. 47, n. 1, p. 43-49, 2001. 
SHIGEMATSU, E. et al. Influência de pré-tratamentos sobre a desidratação osmótica de carambolas. Ciência e Tecnologia de Alimentos, Campinas, São Paulo, Brasil, v. 25, n. 3, p. 536-545, 2005.

SIMAL, S. et al. Simple modelling of air drying curves of fresh and osmotically pre-dehydrated apple cubes. Journal of Food Engineering, Essex, England, v. 33, n. 1-2, p. 139-150, 1997.

TREYBAL, R. E. Mass-transfer operations. Third edition. New York: McGraw-Hill, 1980.

VACAREZZA, L. M.; CHIRIFE, J. On the mechanism of moisture transport during air drying of sugar beet root. Journal of Food Science, Chicago, Illinois, US, v. 40, n. 6, p. 1286-1289, 1975.
WHITAKER, T. W.; CARTER, G. F. Critical notes on the origin and domestication of the cultivated species of Cucurbita. Journal of Botany, London, England, v. 33, n. 1, p. 10-15, 1946.

WHITAKER, T. W.; CUTLER, H. C. Cucurbits and cultures in the Americas. Economic Botany, Bronx, NY, US, v. 19, n. 4, p. 344-349, 1965.

WILLIAM, H. Official Methods of Analysis.11 ed. Washington : Association of Official Analytical Chemists.1970.

WILLIANS, S. Official Methods of Analysis. 14 ed. Arlington, Virginia: Association of Official Analytical Chemists.1984. 